\title{
Nurses' Perceptions of Patient Safety Culture in a Tertiary Hospital in China
}

\author{
Chih Hsuan Huang',2, Niu Niu Lee ${ }^{2}$, Bei Bei Qu², Qi Qi Du², Jiang Mei Chen² and Li Li ${ }^{3 *}$ \\ ${ }^{1}$ Institute of Wuhan Studies, Jianghan University, China \\ ${ }^{2}$ School of Business Administration, Hubei University of Economics, China \\ ${ }^{3}$ College of Law \& Business of Hubei University of Economics, China \\ *Corresponding author: Li Li, College of Law \& Business of Hubei University of Economics, China
}

Submission: 傮 August 23, 2017; Published: 眥 September 20, 2018

\begin{abstract}
The reports of the 19th CPC National Congress on health and health care clearly stated that that it is critically important to establish a comprehensive medical safety in China. As patient safety has become an important and urgent issue in medical care at home and abroad, this research aims to improve patients' medical safety and the quality of medical services by analyzing Sexton et al. [1] Safety Attitude Questionnaire (SAQ) from the viewpoints of professional nurses. The results show that safety climate is highest dimensions of patient safety culture whereas stress recognition is the lowest one. In addition, job satisfaction is conducted to highly influence overall satisfaction of patient safety. Our research suggest that healthcare management should develop appropriate implementation strategies, such as reliable management system, quality working environment, and efficient decompression program, to continuously improve the awareness of safe atmospheres for patients.
\end{abstract}

Keywords: Nursing staff; Patient safety culture; Medical service; Safety attitude questionnaire

Abbreviations: WHO: World Health Organization; SAQ: Safety Attitude Questionnaire; CSS: Culture of Safety Survey; HSOPS: Hospital Survey on Patient Safety

\section{Introduction}

Safety culture is a major issue faced by medical service systems globally. In 2004, the development of safety culture encountered a major turning point when the WHO announced the formal establishment of the "World Alliance for Patient Safety". It was intended to appeal to all members of WHO - civil organizations, experts, and nursing staff - to work together to establish and improve the management of patients' safety. In 2005, the British Council for Safety and Health defined five major factors that affect patient safety: leadership, two-way communication, employee participation, learning culture, and safety responsibilities and attitudes. In 2015, China's National Health and Family Planning Commission Medical Service Guidance Center launched a typical patient safety case with the Chinese Hospital Association [2]. In December of the same year, the "2015 China Patient Safety Conference" was held in Beijing. A safety education training base was set up and participants were educated in the basics of patient safety. It has been proven that the development of educational activities can enhance the awareness of patient safety among medical workers and society at large [2].

In 2017, the reports of the 19th CPC National Congress on health and health care also clearly stated that it is critically important to establish a comprehensive medical security system with Chinese characteristics and a high-quality and efficient medical system in the coming years. Meanwhile, the medical safety of patients should be improved. As patient safety has become an important and urgent issue in medical care at home and abroad, this research aims to improve the quality of medical services and protect patients' medical safety by analysing professional nurses' awareness of safe atmospheres for patients and providing corresponding suggestions.

\section{Literature Review}

With the rise of social concern for patient safety, a series of studies have evaluated safety culture from different angles using different investigation methods, such as Safety Attitude Questionnaire (SAQ), Culture of Safety Survey (CSS), and Hospital Survey on Patient Safety (HSOPS) [1,3-7] As presented in Table 1, Sexton et al. [1] tested and analyzed SAQ repeatedly and divided the scale into six dimensions with thirty questions. Compared with other measurement tools, SAQ has a uniform quantitative standard with a wide application range. Gabrani et al. [8] found that improving nurses' teamwork atmosphere, job satisfaction, and perceptions of management can promote the improvement of patient safety culture by collecting data with SAQ in four regional 
hospitals in Albania. Huang et al. [3] investigated the patient safety culture of a medical institution in central Taiwan with SAQ and indicated that nurses that perceive teamwork among their colleagues pay more attention to safety. The discussion above shows that strengthening nurses' attitudes toward patient safety culture can effectively prevent various medical errors and improve

Table 1: The safety attitudes questionnaire. the quality of medical services. Although studies supported the role that patient safety culture plays in improving medical services in hospitals, little knowledge has clearly identified the key elements for promoting patient safety culture in China. Therefore, SAQ, which is used to measure nurses' awareness of patient safety, was selected as the basis of this study.

\begin{tabular}{|c|c|}
\hline \multirow{3}{*}{ Teamwork } & (1) Nurse input is well received in this clinical area \\
\hline & (2) In this clinical area, it is difficult to speak up if I perceive a problem with patient care ${ }^{(r)}$ \\
\hline & (3) Disagreements in this clinical area are resolved appropriately (i.e. not who is right, but what is best for the patient) \\
\hline \multirow[t]{3}{*}{ Climate } & (4) I have the support I need from other personnel to care for patients \\
\hline & (5) It is easy for personnel here to ask questions when there is something that they do not understand \\
\hline & (6) The physicians and nurses here work together as a well-coordinated team \\
\hline \multirow{7}{*}{ Safety Climate } & (7) I would feel safe being treated here as a patient \\
\hline & (8) Medical errors are handled appropriately in this clinical area \\
\hline & (9) I know the proper channels to direct questions regarding patient safety in this clinical area \\
\hline & (10) I receive appropriate feedback about my performance \\
\hline & (11) In this clinical area, it is difficult to discuss errors ${ }^{(r)}$ \\
\hline & (12) I am encouraged by my colleagues to report any patient safety concerns I may have \\
\hline & (13) The culture in this clinical area makes it easy to learn from the errors of others \\
\hline \multirow{5}{*}{ Job Satisfaction } & (14) I like my job \\
\hline & (15) Working here is like being part of a large family \\
\hline & (16) This is a good place to work \\
\hline & (17) I am proud to work in this clinical area \\
\hline & (18) Morale in this clinical area is high \\
\hline \multirow{4}{*}{ Stress Recognition } & (19) When my workload becomes excessive, my performance is impaired ${ }^{(r)}$ \\
\hline & (20) I am less effective at work when fatigued ${ }^{(r)}$ \\
\hline & (21) I am more likely to make errors in tense or hostile situations (e.g. emergency resuscitation, seizure) ${ }^{(r)}$ \\
\hline & (22) Fatigue impairs my performance during emergency situations $s^{(r)}$ \\
\hline \multirow{4}{*}{ Perceptions of Management } & (23) Managers supports my daily efforts \\
\hline & (24) Managers do not knowingly compromise patient safety \\
\hline & (25) I get adequate, timely information about events that might affect my work \\
\hline & (26) The levels of staffing in this clinical area are sufficient to handle the number of patients \\
\hline \multirow{4}{*}{ Working Conditions } & (27) Problem personnel are dealt with constructively \\
\hline & (28) This hospital does a good job of training new personnel \\
\hline & (29) All the necessary information for diagnostic and therapeutic decisions is routinely available to me \\
\hline & (30) Trainees in my discipline are adequately supervised \\
\hline
\end{tabular}

Note: r: Reversed Question

\section{Research Methods}

\section{Respondents}

One hundred and sixty-six nurses from a tertiary hospital in Wuhan City, China were selected as research subjects in 2017. The respondents were asked to answer the SAQ survey to assess their perceptions of patient safety.

\section{Instrument}

The SAQ developed by Sexton etal. [1] consists of six dimensions: teamwork climate, safety climate, job satisfaction, stress recognition, perceptions of management, and working conditions. Teamwork climate refers to how the respondents feel about mutual cooperation among their colleagues, which is measured using six 
questions. The seven questions pertaining to safety climate pertain to how the respondents feel about their hospital's commitment to safety. The five questions on job satisfaction indicate whether the respondents have positive thoughts about work motivation. Four questions about stress recognition illustrate the respondents' feelings about work pressure. Four questions on perceptions of management query how the respondents feel about the working style of their managers. Four questions on working conditions indicate respondents' feelings about their work environments $[3,4,9]$. In addition, this study added overall patient safety culture satisfaction to explain respondents' overall satisfaction on the construction of patient safety culture in hospitals. All items were measured using a five-point Likert scale anchored at "strongly disagree" and "strongly agree." Regression analysis was used to explore the influence of each dimension of patient safety culture on nurses' overall satisfaction.

\section{Research Results}

\section{Characteristics of respondents}

Female nurses were the largest demographic, accounting for about $92.17 \%$ of respondents. The largest age group was that of 18- to 25-year-old participants, accounting for about $37.25 \%$. The second largest age group was 26- to 30-year-old participants, accounting for $34.34 \%$. About $78.92 \%$ of respondent nurses had a bachelor's degree, and most had 5-10 years of working experience, accounting for $24.70 \%$.

\section{Statistical analysis}

According to the reliability analysis, the Cronbach's $\alpha$ coefficient of all dimensions is greater than 0.7, indicating that the questionnaire is reliable. The mean value of the safety climate was the highest (4.16), indicating that nurses attach great importance to their patients' safety conditions. Secondly, the working condition (4.15) indicates that the nurses are satisfied with their working environment. Thirdly, teamwork climate (4.13) indicates that nurses are good at working with colleagues and working together efficiently in the department. The lowest mean value is stress recognition (2.67), indicating that nursing staff are under greater work pressure. In addition to stress recognition, the average value of the other five dimensions is between 4.00 and 4.16, indicating that nurses have a higher understanding of patient safety culture.

\section{Regression analysis}

According to the regression analysis, only job satisfaction (beta $=0.702, \mathrm{p}=0.000$ ) has a positive significant influence on overall patient safety satisfaction, and other dimensions have no significant impact on overall satisfaction. That is, emotional identification with work or approval from work had a direct impact on whether nurses were satisfied with the implementation of patient safety. Furthermore, the VIF of the collinearity diagnostics was less than 10 ; there is no multicollinearity issue among the dimensions [10] (Table 2).

Table 2: Regression analysis $(n=166)$.

\begin{tabular}{|c|c|c|c|c|c|c|}
\hline & \multirow{2}{*}{$\begin{array}{c}\text { Model } \\
\text { B }\end{array}$} & \multicolumn{2}{|c|}{ Unstandardized Coefficients } & \multirow[t]{2}{*}{ Standardized Coefficients } & \multirow[b]{2}{*}{$\mathrm{t}$} & \multirow[b]{2}{*}{ Sig. } \\
\hline & & $\begin{array}{l}\text { Standard } \\
\text { Error }\end{array}$ & Beta & & & \\
\hline \multirow{7}{*}{1} & (Constant) & 1.282 & 0.496 & & & 0.011 \\
\hline & Teamwork climate & 0.129 & 0.131 & 0.089 & 0.986 & 0.326 \\
\hline & Safety climate & -0.19 & 0.166 & -0.113 & -1.143 & 0.255 \\
\hline & Job satisfaction & 0.817 & 0.102 & 0.702 & 8.033 & 0 \\
\hline & Stress recognition & 0.003 & 0.053 & 0.004 & 0.066 & 0.948 \\
\hline & Perceptions of management & 0.006 & 0.166 & 0.004 & 0.037 & 0.971 \\
\hline & Working conditions & -0.097 & 0.177 & -0.055 & -0.55 & 0.583 \\
\hline
\end{tabular}

Dependent variable: overall patient safety satisfaction

\section{Discussion}

The results show that job satisfaction positively affects nurses' overall satisfaction with patient safety, indicating that most nurses have enthusiasm for their work. There is a certain correlation between stress recognition and job satisfaction with work conditions, indicating that the nursing staff who participated in this study have been under long-term pressure. Stress recognition has a significant correlation with perceptions of management. According to the results of our research, from a psychological point of view, management models and methods directly affect nursing staff and can double or release their work pressure. Based on the results of this study, we make the following suggestions.

\section{Designing management systems to form an effective incentive atmosphere}

Our results show that job satisfaction and overall satisfaction have a high positive correlation, and nurses' job satisfaction affects patients' safety and satisfaction. This shows that developing nurses' positivity towards their work will create a better working atmosphere, achieving their cooperation to improve the quality of nursing and the quality of care. It is particularly necessary to protect patients' safety; this can be incentivized by establishing a management system in which managers are respectful to nursing staff and are willing to accept their advice in their daily work. When nursing staff find it difficult to provide patients with medical 
services, they will feel comfortable expressing their difficulties and seeking the necessary support. On one hand, this can prevent hidden dangers and improve nurses' work enthusiasm. On the other hand, in the units, head nurses and other managers should be capable of defusing situations in the medical department when disagreements arise between the nursing staff or when indistinct questions are asked.

\section{Establishing a quality working environment}

The results of this study also show that nurses' perception of their organization's security gives them a certain sense of security. The higher the acceptance of medical work, the more satisfied the status of the unit is. If we can establish a reliable work guarantee system, in the case of certain contact with patients, doubts related to patient safety can be reported to the department, helping to build a better cultural atmosphere. In fact, a reliable job security system will ensure that patients can receive very safe medical services in the department. From the point of view of the nursing staff, medical errors in the department can be properly handled in a timely and effective manner. There are appropriate channels to directly solve problems related to patient safety, get feedback from the management level, and enhance the effectiveness of the medical team at multiple levels.

\section{Establishing an efficient decompression program}

Furthermore, the results of this study show that nurses' average stress recognition is low by statistical analysis, indicating that the nursing staff in the units are impacted by work stress. When nurses' workloads are too heavy, or when they experience physical and mental fatigue, their work efficiency and performance will be reduced. When pressure from work exceeds the nurses' scope, they may make mistakes which, in turn, may lead to emotional tension, anger or fatigue, and their ability to respond to emergencies will be reduced. Therefore, a complete decompression system should be established including outdoor activities, which will greatly enhance nurses' morale.

\section{Conclusion}

Developing a better patient safety culture is one of the critical issues for every hospital to enhance medical service to maintain competitive advantages in healthcare industry. The current study identifies that job satisfaction is statistically significant factor that cause satisfaction of patient safety culture from professional nurses in a tertiary hospital in China. Our results suggest that more attention to effective management system, quality working environment, and efficient decompression program, to enhance the improvement of patient safety culture satisfaction. The investments of these implications enable hospital managers to inspire medical staff to provide patient-oriented care.

\section{Acknowledgment}

This study was supported by Institute of Wuhan Studies of Jianghan University with the grant number of IWHS20182002.

\section{References}

1. Sexton JB, Helmreich RL, Neilands TB, Rowan KV, Boyden $\mathrm{K}$, et al. (2006) The safety attitudes questionnaire: psychometric properties, benchmarking data, and emerging research. BMC Health Serv Res 6: 44.

2. (2018) National Health and Family Planning Commission of the People's Republic of China (NHC). Health planning reformation and development.

3. Huang $\mathrm{CH}, \mathrm{Wu} \mathrm{HH}$, Lee YC (2018) The perceptions of patient safety culture: A difference between physicians and nurses in Taiwan. Appl Nurs Res 40: 39-44.

4. Lee YC, Huang SC, Huang CH, Wu HH (2016) A new approach to identify high burnout medical staffs by kernel k-means cluster analysis in a regional teaching hospital in Taiwan. Inquiry 53: 0046958016679306.

5. Meddings J, Reichert H, Greene MT, Safdar N, Krein SL, et al. (2017) Evaluation of the association between Hospital Survey on Patient Safety Culture (HSOPS) measures and catheter-associated infections: results of two national collaboratives. BMJ Qual Saf 26(3): 226-235.

6. Weingart SN, Farbstein K, Davis RB, Phillips RS (2004) Using a multihospital survey to examine the safety culture. Jt Comm J Qual Saf 30(3): 125-132.

7. Sorra JS, Dyer N (2010) Multilevel psychometric properties of the AHRQ hospital survey on patient safety culture. BMC Health Serv Res 10: 199.

8. Gabrani A, Hoxha A, Simaku A, Gabrani J (2015) Application of the Safety Attitudes Questionnaire (SAQ) in Albanian hospitals: a cross-sectional study. BMJ Open 5(4): e006528.

9. Lee YC, Shieh JI, Huang CH, Wang CY, Wu HH (2017) Analyzing patient safety culture from viewpoints of physicians and nurses-A case of a regional teaching hospital in Taiwan. Journal for Healthcare Quality 39(5): 294-306.

10. Malik ME, Ghafoor MM, Hafiz KI, Riaz U, Hassan NU, et al. (2013) Importance of brand awareness and brand loyalty in assessing purchase intentions of consumer. International Journal of Business and Social Science 4(5): 167-171.
Creative Commons Attribution 4.0 International License

For possible submissions Click Here

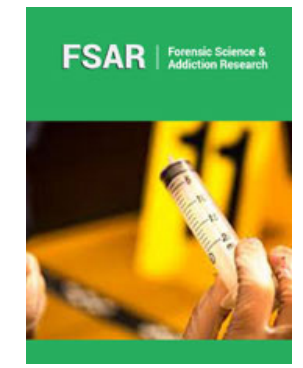

\section{Forensic Science \& Addiction Research}

\section{Benefits of Publishing with us}

- High-level peer review and editorial services

- Freely accessible online immediately upon publication

- Authors retain the copyright to their work

- Licensing it under a Creative Commons license

- Visibility through different online platforms 